teressante do que a de Havana, por não ser feita nesta cidade paulista renhuma desinfecção nem obras de saneamento, como se extcutaram na capital cubana.

Tendo estado sempre o illustre dr. Barretto na linha da frente nos combates decisivos contra o maior inimigo da nossa civilisação, é de inteira justiça lembrar, e eu o faço com o maximo prazer, no momento das suas festas jubilares, quando the são consagradas as merecidas provas de alto apreço e reconhecimento por todas as nossas classes sociaes, os grandes serviços prestados á causa da saude publica.

(Dos Annaes Paulista de Medicina e Cirurgia)

Laboratorio de Anatomia

FACULDADE DE MEDICINA E CIRURGIA DO ESTADO DE S. PAULO

Director: Prof. A. BOVERO

\title{
VARIEDADES DAS VEIAS DA BASE DO PESCOÇO
}

\author{
OBSERVAÇOES DE RAUL MALHEIROS E A. ARRUDA SAMPAIO \\ ( QUARTO-ANNISTAS)
}

E' facto bem sabido que não constitue novidade encontrarem-se muito frequentemente no systema venoso disposições mais ou menos differentes das descriptas nos tratados classicos; e. precisamente por isso, nem sempre é facil a fixação de um typo constante, eschematico para cada districto do systema venoso. O desappareceimento ou a maior accentuação das disposições habituaes, - pequenas anastomoses, por exemplo - são susceptiveis de originar modalidades que representam uma passagem gradual, por vezes insensivel, entre essas disposições mais communs que se consideram portanto como anormaes, e as muitas outras que podem racionalmente ser descriptas como verdadeiras variedades, ou mesmo constituir de todo o ponto anomalias. As asymetrias frequentes sendo constantes observadas em certos grupos venosos são passiveis, é claro, de interpretação á luz do memo criterio.

Parece-nos digna de interesse a disposiçăo algo anormal das veias da base do pescoço, por nós observadas acidentalmente numa preparação de plexo cervical e merecedora, portanto, de rapida descripção. Convictos de que não apresentam as linhas que seguem modalidades extremamente raras ou novidades, quer-nos parecer, repetimos, que estas notas of ferecem interesse, embora diminuto: constituem um simples relatorio da sala de dissecção, não pretendendo ser uma contribuição ao conhecimento do sys- 
tema venoso humano. E' com esta conviç̧ão que apresentamos as notas infras.

O cadaver em que fizemos as observações é o de um individuo robusto (cad. $n .^{\circ} 1168$ ), de nacionalidade italiana, 31 annos de edade, fallecido por pleurizia em 10-5-1922. O cadaver foi injectado, como de costume em nosso Laboratorio, com uma solução conservadora de formol a $\left.10^{\circ}\right|^{\circ}$, pela arteria femoral; assim, ficaram os vasos venosos do pescoço, na maior parte do seu percurso, cheios de sangue coagulado, como por injecção artificial das veias, o que aliás facilitou sobremaneira o seu isolamento.

A disposição das veias jugulares interna e externa apresenta-se differentemente á direita e á esquerda.

A' direita a veia jugular externa se mostra mais calibrosa que a sua homonyma do lado esquerdo. Como nos casos normaes, apresenta-se superficialmente na parte baixa da região parotidiana e constituida pela confluencia de uma v. auricular posterior e de um ramo anstomatico com a v. facial posterior; estando vasias, ambas estas veias apresentam-se muito delgadas.

A veia jugular externa recoberta pelos feixes posteriores, obliquamente ascendentes para dentro, do musculo cuticular do pescoço. criza com um trajecto obliquo para baixo e para fóra, asuperficie lateral do m. esterno-cleido-mastoideu, estando comprehendida num desdobramento do folheto superficial da fascia deste musculo.

Depois, notavelmente augmentada de calibre, attinge a região supraclavicular. cuja fórma triangular apparece nitidamente só após a dissecção; desce com a bissectriz desse triangulo até a base do mesmo, onde mede cerca de $1 \mathrm{~cm}$. de calibre, abrindo-se, depois de perfuradas as facias cervicaes superficial e media, - mais ou menos em frente da margem lateral do musculo escaleno anterior, - no contorno superior da veia subclavia, a $1,5 \mathrm{cms}$. para fóra do ponto de reunião desta com a v. jugular interna.

Ao nivel do apice do triangulo supraclavicular, os nervos transversos do pescoço e supraclaviculares contornam lateralmente e por deante a veia jugular externa.

Recobre ainda, por deante, a extremidade anterior do ventre posterior e o tendão intermedio do musculo omohyoideu, o qual passa, depois, adeante da v. jugular interna para chegar ás suas inserções hyodéas; recobre tambem o ramo descendente do plexo cervical, ramo esse que se encurva para dentro e em seguida para cima, anastomosando-se com o ramo descendente do hypoglosso para formar uma typica alça de concavidade superior, collocada adeante da v. jugular interna.

A jugular externa, logo que attinge a margem posterior do musculo esterno-cleido-mastoideu, isto é, mais ou menos ao nivel do apice do triangulo supraclavicular, com a sua superficie profunda juxtapõe-se e abre-se na parede antero-externa da v. jugular interna, tendo essa fusão immediata uma altura de 1,5 cms., mais ou menos. Desta fusão resulta que, em conjucto, a v. jugular externa se apresenta, não rectilnea, mas descrevendo um angulo fortemente obtuso, aberto para fóra e para traz. Depois desta anastomose por juxtaposição, ou antes, por meio de un tronco extremamente curto, quasi virtual, a v. jugular externa desvia-se para baixo e 
para fóra, de modo a formar, vistas em conjuncto, as suas relaçōes com a v. jugular interna, uma letra $\mathrm{K}$ invertida.

Considerando-se a grossa anastomose entre as duas jugulares e a união destas com a subclavia, resulta a formação de um annel venoso que delimita um espaço triangular, com cerca de $4 \mathrm{cms}$. de altura, o qual é atravessado pelo musculo omohyoideu e pelo ramo descendente interno do plexo cervical com a direcção e as relações acima lembradas.

Por seu lado, o musculo esterno-cleido-mastoideu direito acha-se comprehendido na alça, de concavidade superior, formada pela parte alta da v. jugular externa, que the corre superficialmente, anastomosada por juxtaposição com'a veia jugular interna, que fica profundamente situada em trelaçào ao musculı. A' veia jugular externa direita affluiam, como normalmente na região supraclavicular, as vv. transversa da escapula e do pescoço, como tambem um delgado ramo procedente da jugular anterior do mesmo lado o qual decorre por baixo do musculo esterno- cleidomastoideu.

Quanto ao lado esquerdo, existem disposições differentes no seu conjuncto das precedentes descriptas, faltando completamente a anastomose entre as duas jugulares interna e extrna. A veia jugular intrena, apresentando-se quasi do mesmo calibre que a correspondente da direita, é rectilinea. cruzada em baixo e para deante pelo musculo omohyoideu.

A v. jugular é constituida, como de regra, ao nivel da superficie externa do musculo esterno-cleido-mastoideu, por um tronco ligeiramente sinuoso com cerca de $4 \mathrm{cms}$. de diametro transversal; o qual c:uza depois obliquamente para baixo e para fóra a superficie do mesmo musculo, comprehendida num desdobramento de sua fascia. Chegando ao nivel da margem posterior do musculo, na parte superior do triangulo supraclavicular maior, a v. jugular externa subdivide-se em dois ramos mais ou menos equivalentes de 4,5 a $5 \mathrm{cms}$. de diametro, varicosos, sendo um delles anterior e continuando, para baixo e para dentro, o tronco principal. O outro ramo é posterior e descreve uma curva de convexidade voltada para traz.

Estes dois ramos estão comprehendidos num desdobramento da aponevrose cervical superficial que fecha o triangulo supraclavicular maior. Depois de um trajecto de cerca de $3 \mathrm{cms}$., os ramos de bifurcação da v. jugular externa confluem ainda em um tronco unco como uma fenda iongitudinal; por essa abertura passa um grosso tronco nervoso, piocedente da parte profunda e que se continúa com os nn. supraclaviculares medios e lateraes. A parte inferior do tronco da v. jugular externa, resultante da fusão dos dois ramos descriptos, tem um ca:bre de cerca de $\mathbf{5}$ mms.; perfura a aponevrose cervical superficial, assumindo $u$ m trajecto quasi ho:izontal, de $3 \mathrm{cms}$. de comprimento; recebe. pela sua parte anterior, um calibroso ramo, de percurso tambem loricontal, continuação da v. jugular anterior esquerda, e vae, emfim, desembocar exactamente no angulo diedro, quasi recto, de abertuia voltada para cima e par fóra, delimitado pelas veias jugular interna e suliclavia. Excisivamente ao trunco posterior de bifurcação da v. jugular externa, na par de do triangulo supraclavicular maior, chegam os aflluentes pr.ncipaes. nurmaes da mesma veia, isto é: acima, logo depois da sua origem. e untes da veia ser cruzada pe!os nn. supraclaviculares medios e lateraes, chegra uma grande veia subcutanca anterior do pescoço; na sua parte media, dito tronco pos- 
terior recebe uma vena transversa solli muito calibrosa ( $3 \mathrm{mms}$ ) e varicosa; mais para baixo, ao nivel da confluencia do tronco posterior com o. anterior, e no contorno inferior do tronco posterior, abre-se uma vena transversa scapulae; esta, satiellite da respectiva arteria, a 2,5 ou $3 \mathrm{cms}$. antes da sua abertura nesse ramo posterior da v. jugular externa, já mencionado. Por esta anastomose, o tronco posterior da veia jugular externa e as porções terminaes das rv. transversa colli e transversa scapula delimitam tambem um outro annel venoso, irregular, porém completo e occupado por um bloco de tecido callulo-adiposo.

Do que procede resulta que a porção terminal da veia jugular exterñ. com os seus affluentes, assume uma disposição plexiforme, cujos constituintes estão logo adeante das raizes dos cordões do plexo brachial.

A disseção dos troncos venosos brachios-cephalicos á direita e á esquerda, mostrou-nos disposições normaes, affluindo regularmente á veia cava superior.

Como complemento, devemos accrescentar que no musculo ésternocleidomastoideu da esquerda era possivel distingueir quatro systemas de feixes isolados, no corpo muscular, por intesticios bem nitidos de tecido cellular frouxo: um feixe do esterno-mastoideu, mais superficial e recobrindo os outros; um feixe esterno-occipital; um feixe cleido-mastoideu e um feixe cleido occipital, este ultimo de $3 \mathrm{mms}$., mais ou menos, de largura, mostrando-se isolado e parallelo á margem posterior do cleido-mastoideu até quasi ás suas inserções superiores.

Pelo contrario, a distincção, nas origens do musculo, entre um feixe esternal e um feixe clavicular era muito pouco evidente, faltando um triangulo supraclavicular menor, porque havia continuidade perfeita entre as insercoues esternaes e claviculares. A' direita, a mesma disposição, faltando. porém, distincto o feixe cleido-occipital.

A exposição do comportamento do musculo esterno-cleido-mastoideu sae dos limites destas notas, já tendo sido tratada no presente anno, numa nota dos nossos collegas Gomes Julio e Leme.

O nosso intuito era apenas chamar a atenção, de um modo especial, sobre a disposição que descrevemos, das veias da base do pescoço, e que encontramos casualmente. Por outro lado, é bastante facil analysar as modalidades dessa variação no dispositivo das veias, comparando-as com as descriptas em todos os tratados classicos, quando minucniosos. (Cruveilhier, Sappey, Henle, Poirier. Testut, Chiarugi, Quain, etc.).

São Paulo, 1922. 